\title{
Bronchial responsiveness, lung mechanics, gas transfer, and corticosteroid response in patients with chronic airflow obstruction
}

\author{
A L JAMES, K E FINUCANE, G RYAN, A W MUSK
}

From the Departments of Respiratory Medicine and Pulmonary Physiology, Sir Charles Gairdner Hospital, Nedlands, Western Australia

ABSTRACT Thirty patients with stable chronic airflow obstruction receiving regular bronchodilatoro treatment were studied to determine whether the level of bronchial responsiveness, transfer factor for $\rightarrow$ carbon monoxide (TLCO), or the mechanical properties of the lung predicted a bronchodilator $Z$ response to oral corticosteroid treatment. Before treatment mean (SD) $\mathrm{FEV}_{1}$ was $48 \%(16 \%)$ of the predicted value (\% pred); the geometric mean concentration of methacholine required to produce a3 $20 \%$ fall in $\mathrm{FEV}_{1}\left(\mathrm{PC}_{20}\right)$ was 0.44 (range $\left.0.07-3.32\right) \mathrm{mg} / \mathrm{ml}$; and TLCo was $59 \%(21 \%)$ predicted. The exponential constant $(\mathrm{k})$ defining the shape of the static volume-pressure curve was $146 \%(66 \%) \vec{\bullet}$ predicted and pulmonary conductance relative to predicted lung volume at a transpulmonary pressure of $5 \mathrm{~cm} \mathrm{H}_{2} \mathrm{O}\left(\mathrm{sGL}_{5}\right)$ was $72 \%(37 \%)$ predicted. After prednisolone treatment $\left(0.6 \mathrm{mg} \mathrm{kg}^{-1} \mathrm{O}\right.$ day $^{-1}$ for two weeks) $\mathrm{FEV}_{1}$ increased by $8 \%(19 \%)(\mathrm{p}<0.05)$ and daily mean peak flow (PEF) by $3 \%$ 主 $(10 \%)(\mathrm{p}<0.01)$ over pretreatment values. Three patients had an increase in $\mathrm{FEV}_{1}$ of more than $30 \%$, two of whom had sputum eosinophilia $(\mathrm{p}<0.05)$. The three were among the 13 patients with a reduced $\mathrm{SGL}_{5}$. The increase in $\mathrm{FEV}_{1}$ did not correlate with initial $\mathrm{PC}_{20}(\mathrm{r}=-0 \cdot 16), \mathrm{k}(\mathrm{r}=-0 \cdot 12)$, or $\operatorname{TLCO}(\mathrm{r}=-0 \cdot 14)$. Thus measurements of bronchial responsiveness, lung distensibility, and TLCo did not predict corticosteroid response in patients with stable chronic airflow obstruction. Patients with 3 sputum eosinophilia or reduced pulmonary conductance may be more likely to respond.

\section{Introduction}

In a variable proportion of individuals with chronic

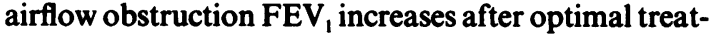
ment with bronchodilators and systemic corticosteroids. ${ }^{1-11}$ Patients' characteristics, such as the acute response to a bronchodilator, ${ }^{211}$ increased blood or sputum eosinophil count, ${ }^{23}$ variability of symptoms and ventilatory capacity, ${ }^{3}$ and a personal or family history of allergy, ${ }^{4}$ have been associated with responsiveness to corticosteroids but none allows accurate prediction of response. A trial of treatment with corticosteroids remains the only definitive method of identifying subjects who will respond. ${ }^{12}{ }^{13} \mathrm{~A}$ means of predicting a response to corticosteroids would be useful.

\footnotetext{
Address for reprint requests: Dr A W Musk, Department of Respiratory Medicine, Sir Charles Gairdner Hospital, Nedlands 6009, WA, Australia.
}

Accepted 6 May 1988
Chronic airflow obstruction may be due to intrinsicon airway narrowing from inflammation, fibrosis of airway walls, or smooth muscle hypertrophy; to loss of 3 . airway support resulting from emphysema; or to ai combination of mechanisms.$^{14}$ Corticosteroids mights be expected to improve airflow obstruction caused byo intrinsic airway narrowing but to have no effect on that due to emphysema. It may therefore be possibleo to predict corticosteroid responsiveness from. measurements that reflect these aspects of lung func- $-\infty$ tion. Intrinsic airway narrowing would be expected ton cause a reduction in pulmonary conductance withN normal lung distensibility ${ }^{15}{ }^{16}$; transfer factor (diffusing ${ }_{\sigma}^{\omega}$ capacity) for carbon monoxide (TLCO) is usually reduced in emphysema, ${ }^{17}$ and normal or increased withe airflow obstruction due to airway disease. Nonspecific bronchial responsiveness is variably increased in asthma and in chronic bronchitis. ${ }^{18}$ In asthma it is related to disease severity and treatment requiremen- $-\vec{\Phi}$ ts $^{19}$ but its significance in chronic bronchitis is lessक्षे clear. ${ }^{2021}$ As bronchial responsiveness is an indicator of 
variability of airflow obstruction it might be expected to predict corticosteroid responsiveness.

We have therefore investigated whether patients with chronic airflow obstruction who respond to corticosteroids can be characterised as having evidence of intrinsic airway narrowing - that is, decreased pulmonary conductance relative to lung elastic recoil pressure, decreased FEV, in the presence of relatively normal TLCO and pulmonary distensibility, and/or increased bronchial responsiveness. Thus we measured the mechanical properties of the lung and non-specific bronchial responsiveness in patients with stable chronic airflow obstruction and related these measures to the change in $\mathrm{FEV}_{1}$ after a course of systemic corticosteroid treatment. We also determined atopy on the basis of prick skin tests with common allergens and examined sputum and blood for eosinophils.

\section{Methods}

\section{SUBJECTS}

Patients with chronic airflow obstruction attending outpatient clinics at the Sir Charles Gairdner Hospital were eligible for inclusion in the study if a trial of steroids was thought indicated by their attending physician and if (1) forced expiratory volume in one second $\left(\mathrm{FEV}_{1}\right)$ was less than $80 \%$ of the predicted value $^{22}$ while they were taking the beta ${ }_{2}$ adrenoreceptor agonist salbutamol (200 $\mu \mathrm{g}$ from a metered dose inhaler or $5 \mathrm{mg}$ by nebuliser at least four times a day) and maximum tolerated doses of slow release theophylline for two weeks; (2) airflow obstruction was stable with no change in symptoms over the previous three months; (3) there was no evidence of cardiac failure or interstitial lung disease from physical examination or chest radiography; and (4) they had not taken oral corticosteroids for at least three months or inhaled corticosteroids for at least one month. All patients gave their informed consent to participating in the study, which was approved by the human rights committee of the University of Western Australia.

\section{INVESTIGATIONS}

Each patient answered the British Medical Research Council (MRC) questionnaire on respiratory symptoms. ${ }^{23}$ Chronic bronchitis was defined as cough or sputum on most days for three months of the year for two or more years. A grade of dyspnoea was obtained from the MRC questionnaire (0-4) and a score for cough frequency based on the method of Field. ${ }^{24}$ We could not obtain a dyspnoea score for one patient because exercise was limited by intermittent claudication.

Prick skin tests were performed with a range of common antigens: rye grass, barley, house dust mite, cat dander, and Aspergillus species ( $A$ niger, $A$ fumigatus, $A$ nidulans, and $A$ terreus; Hollister-Stier, Elkhart, USA). A weal diameter of $3 \mathrm{~mm}$ or more measured 15 minutes after the skinprick was considered a positive result. Subjects with one or more positive results were classified as atopic. A sputum sample was examined for eosinophils. Venous blood was collected for estimation of $\alpha_{1}$ antitrypsin concentration and determination of phenotype, total and differential white blood cell count, and serum theophylline concentration. Sputum eosinophilia was defined as a differential eosinophil count of greater than $5 \%$ and peripheral blood eosinophilia as an absolute count of greater than 0.4 eosinophils $\times 10^{9} / 1$.

After the initial assessment patients measured peak expiratory flow (PEF), using a mini Wright peak flow meter (Clement Clarke, London), each morning and evening, before and 30 minutes after their usual dose of aerosol bronchodilator. On each occasion they recorded the best of three attempts and from the four readings each day the daily mean peak flow rate was calculated.

Maximum expiratory flow-volume curves, forced expiratory volume in one second $\left(\mathrm{FEV}_{1}\right)$, and forced vital capacity (FVC) were measured with a pneumotachograph (Hewlett-Packard 47303A) before and 15 minutes after $200 \mu \mathrm{g}$ isoprenaline or salbutamol. TLCO was measured by the single breath method (PK Morgan, transfer test B). Total lung capacity (TLC) was measured by the method of DuBois ${ }^{25}$ with a pressure compensated "flow" body plethysmograph. ${ }^{26}$ The volume-pressure and conductance-pressure characteristics of the lung were measured during repeated interrupted deflations from TLC. Flow was measured at the mouth and static transpulmonary pressure $\left(P_{s t} L\right)$ as the difference between intraoesophageal ${ }^{27}$ and mouth pressure. To avoid compression of airways during expiration, flow was maintained at values less than maximum expiratory flow by connecting the apparatus to suction and adjusting flow for each patient. At lower lung volumes patients were encouraged to maintain expiratory flow below maximum. Volume-pressure values from TLC to $50 \%$ TLC were fitted to a single exponential function: $V_{\mathbf{L}}=$ $A-B e^{-k P}$, where $V_{L}$ is lung volume; $A, B$, and $k$ are constants; and $P$ is the static transpulmonary pressure at volume $V_{L}$. The constant $k$ is an index of pulmonary distensibility, which is independent of lung size and related to airspace size. ${ }^{28}$ Pulmonary conductance was obtained during interrupted expirations from TLC by relating flow at the time of interruption to change in pressure between the value at the time of interruption and the plateau value obtained during zero flow. ${ }^{15}$ Pulmonary conductance was related to the $P_{s t} \mathrm{~L}$ at which it was measured and the results were fitted with a linear regression curve, from which conductance at a 
transpulmonary pressure of $5 \mathrm{~cm} \mathrm{H}_{2} \mathrm{O}, \mathrm{GL}_{5}$ was derived. ${ }^{15}$ This value was corrected for size by dividing it by the predicted lung volume at a $\mathrm{P}_{\mathrm{st}} \mathrm{L}$ of $5 \mathrm{~cm} \mathrm{H}_{2} \mathrm{O}$ to obtain the specific conductance at this transpulmonary pressure $\left(\mathrm{sGL}_{5}\right)$-which differs from conventional specific conductance as the latter is obtained from measured lung volume. Five patients could not tolerate an oesophageal balloon for measurements of lung mechanics.

Predicted values were calculated from published regression equations for lung volumes, ${ }^{22}$ gas transfer, ${ }^{22}$ and the mechanical properties of the lungs. ${ }^{28}$ For $\mathbf{G L}_{5}$ data obtained from normal subjects ${ }^{15}$ were used for comparisons.

Bronchial responsiveness was measured by using continuous aerosol delivery during tidal breathing. ${ }^{19}$ The test was performed 48 hours after the last use of slow release theophylline and at least six hours after the last use of inhaled beta agonist drugs. Subjects inhaled aerosols of buffered normal saline followed by doubling concentrations of histamine in saline, starting at $0.06 \mathrm{mg} / \mathrm{ml}$, until $\mathrm{FEV}_{1}$ fell by $20 \%$ from the post-saline level. The concentration of histamine that caused a $20 \%$ fall in FEV $\left(\mathrm{PC}_{20}\right)$ was obtained from the dose-response curve by linear interpolation of the last two points.

\section{PROTOCOL}

On entry into the study patients completed a questionnaire, had a clinical assessment, and began daily measurements of peak expiratory flow (which were continued throughout the four week study period). For the first two weeks patients used regular bronchodilator treatment and then added oral prednisolone for a further two weeks. Tests of pulmonary function (before and after bronchodilator) were performed immediately before and after the period of prednisolone treatment.

Prednisolone, $0.6 \mathrm{mg} \mathrm{kg}^{-1} \mathrm{day}^{-1}$ (35-60 mg/day), was given as a single dose each morning for two weeks. Compliance with treatment was assessed by

Table 1 Characteristics of the subjects

No (\%) of subjects

\begin{tabular}{lr}
\hline Smoking & $17(57)$ \\
Current smokers & $13(43)$ \\
Ex-smokers $(>1$ year) & $10(33)$ \\
History of & $8(27)$ \\
Asthma & $2(7)$ \\
Hay fever & $17(57)$ \\
Eczema & $4(13)$ \\
Chronic bronchitis* & $7(23)$ \\
Eosinophilia & $11(37)$ \\
Blood $\left(>0.4 \times 10^{9} / 1\right)$ & $30(100)$ \\
Sputum $(>5 \%)$ & Atopy \\
Total & \\
\hline
\end{tabular}

*Medical Research Council definition. ${ }^{23}$
Table 2 Lung function before and after prednisolone treatment (mean (SD)) values, with \% predicted in square brackets)

\begin{tabular}{|c|c|c|}
\hline & Before treatment & After treatment \\
\hline $\operatorname{FEV}_{1}(1)^{*}$ & $1.35(0.54)$ & $1.46(0.50) \dagger$ \\
\hline $\operatorname{FVC}(1)^{*}$ & $\begin{array}{l}{[48(16)]} \\
3.00(0.87)\end{array}$ & $\begin{array}{r}{[52(16)]} \\
3.25(0.86)\end{array}$ \\
\hline & [77(15)] & {$[86(16)]$} \\
\hline TLC (1) & $7.21 \quad(1.25)$ & $7 \cdot 23(1 \cdot 13)$ \\
\hline $\operatorname{Tlco}\left(\mathrm{ml} \mathrm{min}^{\prime} \mathrm{mm} \mathrm{Hg}\right)^{\prime}$ & $\begin{array}{c}{[117(19)]} \\
15 \cdot 3\end{array}$ & $16 \cdot 3 \quad(6 \cdot 2)$ \\
\hline $1 \mathrm{LCO}(\mathrm{m} / \mathrm{min} \mathrm{mm} \mathrm{ng})$ & [59 (21)] & {$[65(24)]$} \\
\hline $\mathrm{k}\left(\mathrm{cm} \mathrm{H}_{2} \mathrm{O}^{1}\right)$ & $0.230(0.099)$ & $\ddagger$ \\
\hline $\mathrm{GL}_{5}\left(1 \mathrm{~s}^{\prime} \mathrm{cm} \mathrm{H} \mathrm{H}_{2} \mathrm{O}^{\prime}\right)$ & $0.248(0.155)$ & $\ddagger$ \\
\hline & {$[72(37)]$} & \\
\hline $\mathrm{PC}_{20}(\mathrm{mg} / \mathrm{ml})$ & 0.44 & $0 \cdot 59$ \\
\hline
\end{tabular}

*Post-bronchodilator values.

$t \mathrm{p}<0.05$ in the comparison with values before treatment.

Measurements not performed after prednisolone treatment.

$\mathrm{FEV}_{1}$ - forced expiratory volume in one second; FVC - forced vital capacity; TLC - total lung capacity; TLCo-transfer factor;

$\mathrm{k}$-constant used as an index of pulmonary distensibility (see under

"Methods"); $\mathrm{GL}_{5}$-conductance at a transpulmonary pressure of

$5 \mathrm{~cm} \mathrm{H} \mathrm{H}_{2} \mathrm{O} ; \mathrm{PC}_{20}$-provocative concentration of histamine causing $\mathrm{a}-$

$20 \%$ fall in $\mathrm{FEV}_{1}$.

measurement of blood steroid concentrations in $22^{\circ}$ patients, which were consistent with an exogenous source of corticosteroids. ${ }^{29}$

Patients continued treatment with salbutamol (200$400 \mu \mathrm{g}$ from a metered dose inhaler or $5 \mathrm{mg}$ by $\frac{\circ}{\varnothing}$ nebuliser at least four times a day) and theophylline $\varrho$ throughout the study. Two patients were unable to $\overrightarrow{\overrightarrow{0}}$ tolerate theophylline owing to nausea. Mean (SD) plasma theophylline concentrations were $9 \cdot 3(3 \cdot 7) \mathrm{g} / \mathrm{l}$ in patients taking theophylline. Two patients took ipratropium bromide, $20-40 \mu \mathrm{g}$ four hourly, from a metered dose inhaler in addition to theophylline and salbutamol.

\section{DATA ANALYSIS}

Response to prednisolone was expressed as the percentage change in postbronchodilator $\mathrm{FEV}_{1}$ immediately before and after prednisolone and as the percentage $\frac{}{5}$ change in the mean daily PEF for seven days, $\rightarrow$ measured before and during the second week of treatment with prednisolone. Paired $t$ tests were used $N$ for estimating the significance of the change in FEV and PEF with steroid treatment. The relation of these $D$ changes to measures of lung function before steroid $\omega$ treatment was calculated by regression analysis for continuous variables and cross tabulation with $\chi^{2} \circ$ analysis for categorical variables. Log transformation $\mathbb{D}$ of $\mathbf{P C}_{20}$ was used for statistical analysis.

\section{Results}

Of the 30 subjects $(27$ male, three female, mean (SD) $\stackrel{\mathbb{D}}{\varrho}$ age 62 (7) years-table 1), 10 answered "Yes" when? 


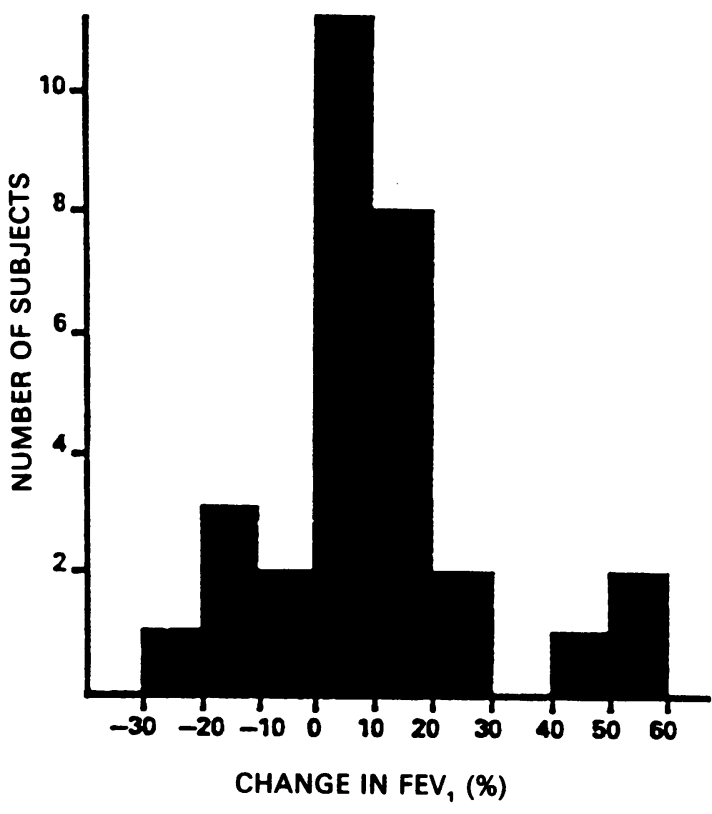

Fig 1 Distribution of responses to prednisolone treatment expressed as percentage changes in postbronchodilator $F E V_{1}$ (30 subjects).

asked if they had ever had asthma. Some also fulfilled the MRC criteria for chronic bronchitis. No patient had $\alpha_{1}$ antitrypsin deficiency. The mean FEV response to bronchodilator before the start of prednisolone was $11 \%$ (SD 14\%). In general, pulmonary distensibility was increased and pulmonary conductance decreased (table 2). Thirteen subjects had evidence of intrinsic narrowing of airways defined by an $\mathrm{sGL}_{5}$ of $<0.05 \mathrm{~s}^{-1}$ $\mathrm{cm} \mathrm{H}_{2} \mathrm{O}^{-1}$. The constant $\mathrm{k}$ was related to TLCo $(\mathrm{r}=$ $-0.54, p<0.01)$ but not to $\mathrm{sG}_{5}(r=0.10) . \mathrm{PC}_{20}$ was not significantly related to the pre-saline $\mathrm{FEV}_{1}$ or to the acute FEV, response to salbutamol.

After treatment with prednisolone mean (SD) $\mathrm{FEV}_{1}$ post-bronchodilator increased by $8 \%(19 \%)$ (p < $0.05)$ (fig 1) and mean daily PEF by $3 \%(10 \%)$ (p < $0.01)$. There was no significant relation between baseline $\mathrm{FEV}_{1}$ and the response to prednisolone ( $\mathrm{r}=$ - 0.07). Cough score decreased in 14 patients, was unchanged in 11, and increased in five ( $p>0.05)$. Dyspnoea grade increased in two patients, decreased in eight and was unchanged in $19(p>0.05)$. The acute responses to a bronchodilator did not change significantly during $(\mathrm{PEF})$ or after $\left(\mathrm{FEV}_{1}\right)$ treatment with prednisolone. Changes in FEV, PEF, and symptom scores with prednisolone treatment were not related to atopy, blood eosinophilia, or response of FEV, to aerosol bronchodilator.

Three patients (baseline FEV $0.73,0.63$, and 1.13 litres) had an increase in $\mathrm{FEV}_{1}$ of more than $30 \%$ from the initial value after prednisolone (fig 1). These patients were among the 13 subjects with an $\mathrm{sGL}_{\mathrm{s}}$ less than $0.05 \mathrm{~s}^{-1} \mathrm{~cm} \mathrm{H}_{2} \mathrm{O}^{-1}$ (fig 2c). This pattern was observed whether conductance was expressed as measured $G_{L}$ or the GL-P $P_{s t}$ slope. Change in $F_{E V}$ was not related to initial $\mathrm{PC}_{20}, \mathbf{k}, \mathrm{sG}_{\mathrm{s}}$, or TLCO (fig 2). Multiple regression analysis showed no relation between $\mathrm{PC}_{20}, \mathrm{k}$, TLCo or $\mathrm{SGL}_{5}$ and either the FEV $\mathrm{V}_{1}$ or PEF response to prednisolone. The patients with more than a $30 \%$ response were not distinguishable on the basis of a past history of asthma (two "Yes", one "No"), chronic bronchitis (two "Yes," one "No"), serum IgE, prick skin test responses, or blood eosinophilia and none of the three had a greater than $20 \%$ response to inhaled bronchodilators at the start of the study. In the two whose sputum was available for examination eosinophil numbers were increased $(80 \%$ and $20 \%$ of white cells). This was more common than in patients with less than a $30 \%$ response to steroids (three of $22 ; \chi^{2}=4.43, p<0.05$ ).

\section{Discussion}

In this group of 30 patients with stable severe chronic airflow obstruction only three patients achieved an increase in $\mathrm{FEV}_{1}$ of $>30 \%$ after a course of systemic corticosteroids, a response rate similar to that found in other studies. ${ }^{1-7}$ The three subjects who responded to corticosteroids were among the thirteen patients who had a $\mathrm{sGL}_{5}<0.05 \mathrm{~s}^{-1} \mathrm{~cm} \mathrm{H}_{2} \mathrm{O}^{-1}$, indicating intrinsic airway narrowing. This suggests that only a minority of subjects with intrinsic airway narrowing will respond to steroids.

Various measures have been associated with a response to systemic corticosteroids previously, ${ }^{1-111}$ but this is the first study to use the relation between $\mathrm{GL}_{\mathrm{L}}$ and $P_{s t} L$ to define the presence of intrinsic airway disease and examine its value in predicting the response to treatment with corticosteroids. The results suggest that the measurement has a low predictive value. Further, there was no significant association

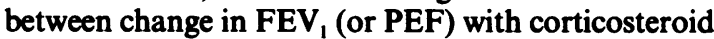
treatment and lung distensibility, gas transfer, or bronchial responsiveness to histamine.

Patients with features that may predict variable airflow obstruction such as a personal or family history of asthma, blood eosinophilia, and a greater than $15 \%$ response to a bronchodilator were included in the study. In some but not all studies these characteristics have been associated with a response to corticosteroids. ${ }^{1411}$ In the present study sputum eosinophilia ( $>5 \%$ white cells) was more common in those who responded to prednisolone, although there was substantial overlap with those who did not respond. Patient selection and varying criteria for defining steroid responsiveness may account for the variation 

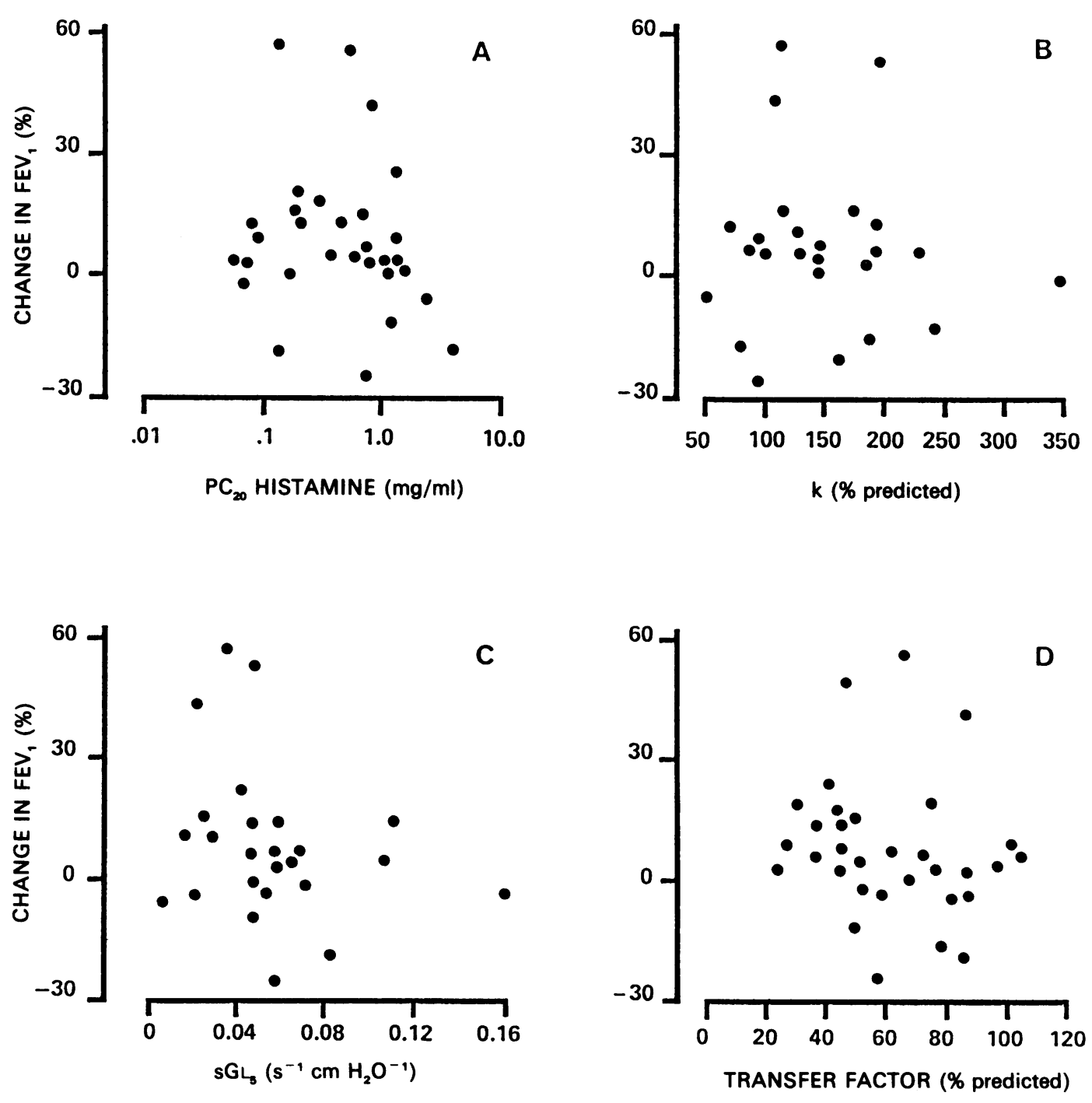

Fig 2 Relation of change in postbronchodilator FEV $V_{1}$ (expressed as the percentage change of the value after corticosteroid $\frac{D}{2}$ treatment from the pretreatment value) and pretreatment levels of $(a)$ bronchial responsiveness to inhaled histamine $\left(P C_{20}\right)$. $r=-0 \cdot 16 ;(b)$ pulmonary distensibility $(k), r=-0 \cdot 12 ;$ (c) specific conductance at $5 \mathrm{~cm} \mathrm{H}_{2} \mathrm{O}$ transpulmonary pressure $\mathrm{O}^{N}$ $\left(s G \mathrm{~L}_{5}\right), r=-0 \cdot 18 ;(d)$ transfer factor for carbon monoxide (TLCO), $r=-0 \cdot 14$.

between studies. Although we used criteria similar to those of Mendella et al $^{1}$ to define a response to corticosteroids, they found a relation between the acute response to a bronchodilator before steroid treatment and the subsequent response to steroids. The dose and duration of treatment with prednisolone in this study was similar to or greater than those in previous studies and are unlikely to explain the small response rate we observed or the differences between this and previous studies.
We used the $\mathrm{FEV}_{1}$ after $200 \mu \mathrm{g}$ of salbutamol ang mean PEF to assess corticosteroid response. These indices may be insensitive to change in airway functiog as random variation in spirometric indices and iq bronchodilator response are well recognised in patients with chronic airflow obstruction. The changes in $\mathrm{FEV}_{1}$, however, the usual measurement used, werc consistent with the small changes in the more frêt quently measured mean PEF.

Lack of any association between non-specific bron 
chial responsiveness and the response to corticosteroids has been previously reported. ${ }^{910}$ Gove et al, using methods similar to ours, found that subjects whose $\mathrm{FEV}_{1}$ increased by more than $20 \%$ with prednisolone had an almost 10 fold lower $\mathbf{P C}_{20}$ (that is, greater bronchial responsiveness) than subjects with an increase of $20 \%$ or less, but the differences were not significant. ${ }^{10}$

The implication of this and previous studies is that it is difficult to predict from clinical and functional characteristics which patients with chronic airflow obstruction will respond to corticosteroid treatment. Our study suggests that patients who respond to corticosteroids are more likely to have sputum eosinophilia and reduced pulmonary conductance, but these measurements have a low predictive value. Assessment of intrinsic airway narrowing and measurements of bronchial responsiveness are unlikely to help select patients who will respond to corticosteroids. The practice of giving a course of steroids to all patients with symptoms attributable to chronic airflow obstruction is likely to continue,,$^{1213}$ despite the low rate of response and the risk of side effects, albeit small with the recommended dose and duration of treatment. Eliasson and colleagues ${ }^{30}$ have questioned the value of corticosteroids in these patients because the response is so small and obtained by a dose of prednisolone that is unacceptable for long term treatment. More information is required on the long term benefits of a short term response to steroids in terms of maintenance of improved lung function, reduced morbidity from chronic airflow limitation, and improved survival.

This study was conducted with a grant from the Asthma Foundation of Western Australia Inc. The help of Dr J M Potter, Robin Gillon, Elizabeth Bingle, and the staff of the departments of pulmonary physiology and pharmacology is gratefully acknowledged.

\section{References}

1 Mendella LA, Manfreda J, Warren CPW, Anthonisen NR. Steroid response in stable chronic obstructive pulmonary disease. Ann Intern Med 1982;96:17-21.

2 Shim C, Stover DE, William MH. Response to corticosteroids in chronic bronchitis. J Allergy Clin Immunol 1978;62:363-7.

3 Harding SM, Freedman S. A comparison of oral and inhaled steroids in patients with chronic airways obstruction: features determining response. Thorax 1978; 33:214-8.

4 Freedman BJ. Bronchodilators and corticosteroids in chronic bronchitis and emphysema. Br Med J 1963;ii: 1509-12.
5 Beerel F, Jick H, Tyler JM. A controlled study of the effect of prednisone on airflow obstruction in severe pulmonary emphysema. N Engl J Med 1963;268: 226-30.

6 Lam WK, So SY, Yu DYC. Response to oral corticosteroids in chronic airflow obstruction. Br J Dis Chest 1983;77:189-98.

7 Franklin W, Michelson AL, Lowel FC, Schilten IW. Bronchodilators and corticosteroids in the treatment of obstructive pulmonary emphysema. $N$ Engl J Med 1958;238:774-7.

8 Morgan WKC, Rusche E. A controlled trial of the effect of steroids in obstructive airway disease. Ann Intern Med 1964;61:248-54.

9 Oppenheimer EA, Rigatto M, Fletcher GM. Airways obstruction before and after isoprenaline, histamine and prednisone in patients with chronic obstructive bronchitis. Lancet 1968;i:552-7.

10 Gove RI, Shepherd J, Burge PS. Bronchial hyperreactivity in corticosteroid responsive patients with chronic airflow obstruction [abstract]. Thorax 1984; 39:695.

11 Blair GP, Light RN. Treatment of chronic obstructive pulmonary disease with corticosteroids. Comparison of daily vs alternate-day therapy. Chest 1984;86:524-8.

12 Sahn SA. Corticosteroids in chronic bronchitis and pulmonary emphysema. Ann Intern Med 1982;96: 17-21.

13 Rudd R. Corticosteroids in chronic bronchitis. Br Med J 1984;288:1553-4.

14 Reid L. Pathological changes in asthma. In: Clark TJH, Godfrey S, eds. Asthma. London: Chapman and Hall, 1977:79-95.

15 Colebatch HJH, Finucane KE, Smith MM. Pulmonary conductance and elastic recoil relationships in asthma and emphysema. J Appl Physiol 1973;34:143-53.

16 Finucane KE, Colebatch HJH. Elastic behaviour of the lung in patients with airway obstruction.J Appl Physiol 1969;26:330-8.

17 Berend NC, Woolcock AJ, Marlin GE. Correlation between the function and structure of the lungs in smokers. Am Rev Respir Dis 1979;119:695-705.

18 Boushey HA, Holtzman MJ, Sheller JR, Nadel JA. Bronchial hyperreactivity. Am Rev Respir Dis 1980; 121:389-413.

19 Hargreave FE, Ryan G, Thomson NC, et al. Bronchial responsiveness to histamine or methacholine in asthma: measurement and clinical significance. $J$ Allergy Clin Immunol 1981;68:347-55.

20 Ramsdale EH, Morris MM, Roberts RS, Hargreave FE. Bronchial responsiveness to methacholine in chronic bronchitis: relationship to airflow obstruction and cold air responsiveness. Thorax 1984;39:912-8.

21 Yan C, Salome CM, Woolcock AJ. Prevalence and nature of bronchial hyperresponsiveness in subjects with chronic obstructive pulmonary disease. Am Rev Respir Dis 1985;132:25-9.

22 Cotes JE. Lung function. Assessment and application in medicine. 3rd ed. Oxford: Blackwell Scientific Publications, 1975:380-1.

23 Medical Research Council Committee on the Aetiology of Chronic Bronchitis. Standardised questionnaire on 
respiratory symptoms. Br Med J 1960;ii: 1965.

24 Field GB. The application of a quantitative estimate of cough frequency to epidemiological surveys. Int $J$ Epidemiol 1974;3:135-43.

25 DuBois AB, Botelho HY, Bedell GN, Marshall R, Comroe JH Jr. A rapid plethysmographic method for measuring thoracic gas volume: a comparison with a nitrogen washout method for measuring functional residual capacity in normal subjects. $J$ Clin Invest 1956;35:322-6.

26 Finucane KE, Mead J. Estimation of alveolar pressure during forced oscillation of the respiratory system. J Appl Physiol 1975;38:531-7.

27 Milic-Emili J, Mead J, Turner JM, Glausser EM.
Improved technique for estimating pleural pressure? from oesophageal balloons. J Appl Physiol 1964;190 207-11.

28 Colebatch HJH, Greaves IA, Ng CKY. Exponentia analysis of elastic recoil and aging in healthy males ando females. J Appl Physiol 1979;47:683-91.

29 Potter JM, Bower GD. Prednisolone pharmacokinetics in children with nephrotic syndrome: studies in relapse and remission. Clin Exp Pharmacol Physiol 1981;6:623-4.

30 Eliasson $O$, Hoffman $J$, Trueb $D$, Frederick $D \stackrel{\text {, }}{2}$ McCormick JR. Corticosteroids in COPD. A clinica trial and reassessment of the literature. Chest 1986;4; 484-90. 